\section{A INTERFERÊNCIA RELATIVA DAS AVÓS NO ALEITAMENTO MATERNO DE SUAS FILHAS ADOLESCENTES}

\author{
Grandmothers' relative interference with their teenage \\ daughter's breastfeeding
}

\section{La interferencia relativa de las abuelas para la lactancia materna de sus hijas adolescentes}

\section{RESUMO}

Objetivo: Compreender influência das avós no exercício e duração do aleitamento materno de suas filhas adolescentes, durante os primeiros seis meses de vida da criança. Métodos: Estudo qualitativo, realizado com 25 futuras avós, que conviviam com suas filhas ou noras adolescentes grávidas, antes e após o nascimento de seus netos, no período de março de 2011 a janeiro de 2014. As entrevistas foram guiadas por um roteiro semiestruturado, e uma vez transcritas foram analisadas de forma temática, da qual emergiu a categoria: "O processo de amamentar para as avós". Resultados: As avós mostraram-se presentes na amamentação de seus netos desde os momentos iniciais até a introdução de alimentos complementares e as suas experiências pessoais de sucesso no aleitamento materno foram importantes para a construção do apoio à nutriz adolescente. Com passar do tempo, as avós se posicionaram na retaguarda, permitindo que as adolescentes assumissem a responsabilidade de principais cuidadoras dos bebês. Conclusão: A influência das avós na amamentação de seus netos se deu pela crença compartilhada que amamentar é importante, saudável e uma obrigação da mãe.

Descritores: Aleitamento Materno; Adolescente; Relação entre Gerações; Saúde da Mulher.

\section{ABSTRACT}

Objective: To understand the influence of grandmothers on the effectiveness and duration of breastfeeding of their teenage daughters during the child's first six months of life. Methods: Qualitative study conducted with 25 new grandmothers who lived with their pregnant teenage daughters or daughters-in-law before and after the birth of their grandchildren from March 2011 to January 2014. The interviews were guided by a semi-structured questionnaire; after transcription, data underwent thematic analysis, which yielded the category: "the breastfeeding process for grandmothers." Results: Grandmothers were present during the breastfeeding of their grandchildren from the earliest moments to the introduction of complementary foods; successful personal experiences with breastfeeding were important for building support for the nursing teenage mother. Over time, they stepped back and allowed the teenagers to take responsibility as the primary caregivers of the babies. Conclusion: The influence of grandmothers on the breastfeeding of their grandchildren is a result of the shared belief that breastfeeding is important, healthy and a mother's obligation.

Descriptors: Breast Feeding; Adolescent; Intergenerational Relations; Women's Health.
Artigo Original

Patricia Helena Breno Queiroz ${ }^{(1)}$ Maria de Lurdes Zanolli(2) Roberto Teixeira Mendes ${ }^{(2)}$

1) Faculdade de Jaguariúna - FAJ Jaguariúna (SP) - Brasil

2) Universidade Estadual de Campinas UNICAMP - Campinas (SP) - Brasil

Recebido em: 17/04/2016

Revisado em: 02/05/2016

Aceito em: 20/06/2016 


\section{RESUMEN}

Objetivo: Comprender la influencia de las abuelas en el ejercicio y la duración del amamantamiento materno de sus hijas adolescentes durante los primeros seis meses de vida del niño. Métodos: Estudio cualitativo realizado con 25 futuras abuelas que convivian con sus hijas o nueras adolescentes embarazadas antes y después del nacimiento de sus netos en el período entre marzo de 2011 y enero de 2014. Se utilizó para las entrevistas un guión semiestructurado y tras la transcripción las mismas fueron analizadas a través de temática de la cual emergió la categoría: "El proceso del amamantamiento para las abuelas". Resultados: Las abuelas estuvieron presentes durante el amamantamiento de sus nietos desde los primeros momentos hasta la introducción de los alimentos complementarios. Las experiencias personales de éxito para el amamantamiento materno fueron importantes para la construcción del apoyo a la adolescente y a lo largo del tiempo se pusieron en retaguardia permitiendo que las adolescentes asumieran la responsabilidad de principales cuidadoras de los bebés. Conclusión: La influencia de las abuelas para el amamantamiento de sus nietos se dio por la creencia compartida de que amamantar es importante y saludable y es una obligación de la madre.

Descriptores: Lactancia Materna; Adolescente; Relaciones Intergeneracionales; Salud de la Mujer.

\section{INTRODUÇÃO}

Amamentar é um processo multifatorial, influenciado pelo ambiente e pela cultura. Sua duração depende, provavelmente, mais da escolha consciente e fundamentada da mãe do que da orientação e apoio antes e depois do nascimento do bebê ${ }^{(1)}$.

Especialistas reunidos pela Organização Mundial de Saúde (OMS) em 2001 analisaram as evidências científicas sobre o período ideal de duração do aleitamento materno exclusivo (AME) e recomendam, desde então, que o aleitamento materno seja exclusivo durante os seis primeiros meses de vida e que a partir daí sejam introduzidos alimentos complementares com a continuidade da amamentação ${ }^{(2)}$.

De acordo com um levantamento global mais de $80 \%$ das mulheres amamentam seus filhos, mas as taxas de AME são bastante inferiores a $50 \%^{(3)}$. No Brasil a prevalência de AME foi de 41,0\% de acordo com a II Pesquisa de Prevalência de Aleitamento Materno nas Capitais Brasileiras e Distrito Federal ${ }^{(4)}$.

Segundo a Academia Americana de Pediatria, as contraindicações para a prática são poucas, mas existem. Não podem amamentar mães: com doenças graves, crônicas ou debilitantes; infectadas pelo vírus da imunodeficiência humana; que precisam tomar medicamentos nocivos para os bebês e, ainda, bebês portadores de doenças metabólicas $\operatorname{raras}^{(5)}$.

Amamentar é uma habilidade que se aprende ${ }^{(1)}$. Por isso, é importante a ação sistemática de profissionais de saúde comprometidos com o tema durante toda a vida reprodutiva da mulher, durante a atenção pré-natal e até seis meses de vida do bebê $\hat{~}^{(1)}$.

Adolescência tem como definição usual o período de vida humana entre a infância e a vida adulta ${ }^{(6)}$. O Fundo das Nações Unidas para a Infância (UNICEF) a considera como o período de vida que se inicia aos 10 e termina aos 19 anos. Muito mais que um rito de passagem, é um período de intensas mudanças caracterizado pelo desenvolvimento físico, mental, emocional, sexual, social e pelos esforços do indivíduo em alcançar os objetivos relacionados às expectativas culturais da sociedade em que vive ${ }^{(7)}$.

Segundo dados do Departamento de Informática do SUS (DATASUS), órgão da Secretaria Executiva do Ministério da Saúde, 19,3\% dos nascidos vivos no país em 2014 tinham mães na faixa etária entre 10 e 19 anos. No estado de São Paulo, a taxa foi de $14,8 \%$ de nascidos $\operatorname{vivos}^{(8)}$.

A gestação e a adolescência, concomitantes ou não, são eventos com especificidades diversas e agregam um universo de mudanças internas e externas. A precocidade na vivência do papel de mãe implica na vivência do papel de avó, que contribui para uma reorganização familiar ${ }^{(9)}$.

Essas avós integram uma geração precursora de mulheres que viveram mudanças significativas pautadas pelo aumento do grau de escolarização e pela sua inserção no trabalho remunerado, garantem a sua independência e autonomia, mas estão totalmente preenchidas de tarefas, tornando mais difícil a conciliação com as demandas da gestação precoce de seus filhos ${ }^{(10)}$.

As avós são um fator importante da família em expansão, pois contribuem ativamente para a formação e crescimento de seus netos ao compartilharem o cuidado, transmitirem conhecimento e contribuindo ativamente na sua criação ${ }^{(11)}$.

A decisão pessoal da mãe em amamentar é apoiada com a informação atualizada e compreensível de como a amamentação influencia em curto e longo prazo, o estado de saúde de seu filho. Profissionais de saúde tem um papel importante em todo o processo e são as pessoas mais próximas que vivem o Aleitamento Materno com a mulher e o bebê. Portanto, é justificável a investigação do papel das avós na amamentação, principalmente quando além de inexperientes como mães, as lactantes são também adolescentes.

Partindo-se do pressuposto de que avós poderiam interferir na amamentação de seus netos, desenvolveu-se 
uma pesquisa com objetivo de compreender influência das avós, no exercício e duração do aleitamento materno de suas filhas adolescentes, durante os primeiros seis meses de vida da criança.

\section{MÉTODOS}

A pesquisa seguiu um delineamento de caráter exploratório e de natureza qualitativa ${ }^{(12)}$ com avós, mães ou sogras de adolescentes atendidas no Ambulatório de Gestação de Alto-Risco da Secretaria Municipal de Saúde de um município da região metropolitana de Campinas, São Paulo, Brasil, e conduzida entre março de 2011 até janeiro de 2014.

O tamanho da amostra foi definido em função das respostas obtidas e participaram do estudo 25 duplas de adolescentes e suas mães ou sogras, que a partir do último trimestre de gestação foram convidadas a participar da pesquisa. Como critério de inclusão, as adolescentes (entre 14 e 18 anos) deveriam ser primigestas e ter convívio regular, ou seja, residir na mesma casa ou nas proximidades das futuras avós maternas ou paternas de seus bebês.

Todas as mulheres foram informadas sobre as características do estudo e seus objetivos e entrevistadas individualmente. As adolescentes concordaram em participar conforme um Termo de Assentimento Livre e Esclarecido (TALE) e as adultas, por um Termo de Consentimento Livre e Esclarecido (TCLE).

As mulheres adultas, apontadas pelas adolescentes, tiveram sua primeira entrevista agendada por contato telefônico prévio, através de números de telefones informados pelas jovens.

Cinco entrevistas foram então agendadas com cada mulher individualmente, obedecendo à conveniência de horário e local indicados pelas entrevistadas. A primeira ocorreu durante o terceiro trimestre de gestação, a segunda, durante o puerpério imediato e as demais aos 30 dias, 120 dias e 180 dias após o nascimento, nas residências das entrevistadas. Os intervalos entre as entrevistas foram escolhidos baseados na literatura, que aponta um declínio do AME no decorrer do tempo.

O roteiro de entrevista semiestruturado continha perguntas disparadoras feitas às avós para que rememorassem a experiência de amamentar mais de um filho e como esta vivência poderia influenciar na amamentação de seus netos. As entrevistas foram gravadas por uma única entrevistadora, em um equipamento digital marca Sony ICD-PX240 ${ }^{\circledR}$, sem tempo de duração pré-estabelecido.

As transcrições das falas foram feitas pela entrevistadora que sistematicamente as recortou e agrupou em unidades de registro, que para efeito de análise, foram reagrupadas, interpretadas e conformadas na categoria eleita para o estudo $^{(13)}$ : "O processo de amamentar para as avós".

A Análise de Conteúdo ${ }^{(14)}$ foi utilizada para se "descobrir os 'núcleos de sentido' que compõem a comunicação, e cuja presença ou frequência podem significar alguma coisa para o objetivo analítico escolhido". Após a exploração do material obtido nas entrevistas, as falas das avós foram, para efeito de análise, reagrupadas nas seguintes subcategorias temáticas: o significado, o conhecimento, o desejo, a prática e o apoio da amamentação.

$\mathrm{O}$ protocolo de pesquisa submetido à revisão ética pelo Comitê de Ética em Pesquisa (CEP) das Faculdades de Ciência Médicas (FCM) da Universidade Estadual de Campinas (UNICAMP) foi aprovado sob o parecer 0031.0.146.000-11. Para preservar as identidades das participantes, seus nomes foram substituídos por nomes de estrelas da Via Láctea.

\section{RESULTADOS E DISCUSSÃO}

\section{O processo de amamentar para as avós}

Primeira subcategoria temática: o significado da amamentação

O ambiente familiar é o lugar onde se aprende os primeiros conceitos de saúde e onde tradicionalmente são as mulheres as responsáveis pela higiene, alimentação e cuidado dos indivíduos. Seus componentes compartilham vivências, ensinamentos e inspiram condutas ${ }^{(15)}$, o que indica ser este o espaço onde as mulheres buscam apoio para o desenvolvimento das atividades maternas e para o aleitamento.

Uma vez que em sua maioria as futuras avós haviam amamentado, possuíam conceitos já elaborados sobre o AM e viam a prática de uma forma positiva:

" [...] É dar de mamar para o bebê, né? [ ...] sim os três [...] foi maravilhoso (fecha os olhos) lembro até hoje [...]." (Pysix)

“[...] É bom né? Pra mim foi, eu gostei de amamentar as meninas [...]." (Norma)

No entanto, duas futuras avós manifestaram aversão ao aleitamento:

“ [...] Eu tenho nojo, não gosto nem de pensar (simula um arrepio) [ ...] não, não quis, (amamentar) [...]." (Pismis)

"[...] Bom... pra mim é dificil, porque eu tenho um trauma, [...] quando eu tinha uns cinco anos mais ou menos, uma amiga da minha mãe me fez mamar nela, eu vomitei muito, tenho nojo até hoje [...]." (Sagita)

O comportamento alimentar de um indivíduo é aprendido e evolui influenciado pelo desenvolvimento, 
pelo contexto social, por fatores emocionais e pela interação familiar ${ }^{(16)}$. Experiências emocionalmente ruins relacionadas com determinado alimento levam a sua rejeição independentemente das qualidades organolépticas que ele possua.

Mais uma vez é oportuno registrar como os condicionantes pessoais influenciam nas escolhas alimentares, que as mulheres fazem para si e para os seus, visto ser o aleitamento uma atitude possuidora de particularidades resultantes das experiências pessoais de cada mulher ${ }^{(1)}$.

\section{Segunda subcategoria temática: o conhecimento sobre o aleitamento}

As futuras avós relataram que não foram orientadas sobre o AM durante a sua assistência pré-natal, mas mencionam a experiência de suas próprias mães e de profissionais de saúde, após o parto:

"[...] No hospital eles falava muito, dai quando eu ia pra casa a minha mãe ajudava [...]." (Taurus)

"[...] Não, eu vi minha mãe amamentar os meus irmãos e quando foi a minha vez eu repeti [...]".,(Câncer)

Um estudo comparativo entre dois grupos de gestantes, quando um recebeu informações sobre AM durante o prénatal e o outro não, encontrou maior percentagem de mães amamentando no final de quatro meses no primeiro grupo ${ }^{(17)}$.

A mulher só poderá decidir de modo favorável ou não em amamentar seu filho se possuir informação sobre o tema. Sua motivação será condicionada pela história familiar, pelo conhecimento adquirido desde a infância, pela oportunidade em observar alguém da família amamentando, pelo que foi aprendido e facilitado no contexto das oportunidades socioculturais e, finalmente, pelo conhecimento adquirido durante a assistência pré-natal ${ }^{(18)}$. Para que a amamentação se concretize é necessário também que a mulher seja instruída sobre os benefícios do AM para seu filho e para ela mesma.

\section{Terceira subcategoria temática: o desejo de amamentar}

Quando perguntadas sobre o desejo em amamentar, as futuras avós relataram não terem refletido sobre o assunto, uma vez que amamentar era a ação esperada para uma mãe, não cabendo questionamento para o cumprimento deste papel:

"[...] Eu não pensei no querer, tinha que dar, fazia parte de ser mãe, mãe tem que amamentar [...]." (Norma)

“[...] Olha, eu pus no peito e amamentei. Num pensei em nada porque era pra fazer e eu fiz [...]." (Leppus)
As falas das futuras avós refletem o meio em que vivem e onde criam seus filhos. Ao considerar a amamentação como inerente à maternidade, talvez expressem um comportamento socialmente esperado ou um discurso adequado ao papel de mãe e nutriz.

Ao medir o nível de informação materna sobre amamentação ${ }^{(19)}$ entre as mulheres que participam do programa de pré-natal na Maternidade Escola, pesquisadores relataram que a expressão do desejo de amamentar era justificada com explicações sobre os benefícios para o bebê, tornando o elemento central deste processo e a mãe, a pessoa que escolhe e se propõe em fazê-lo, toma um papel coadjuvante.

\section{Quarta subcategoria temática: a prática do aleitamento}

A prática do AM foi descrita como uma experiência boa e importante na construção do apego. Sob o ponto de vista das avós, amamentar está relacionado à saúde, proteção e traz benefícios também para a própria lactante:

“[...] Acho, é uma experiência muito boa [...] porque você cria um laço[...] você sente segurança em cuidar do bebê e também é muito prático (risada) [...]." (Sculptor)

"[...] Faz bem pra gente, pro filho, a gente fica mais apegado, eles ficam mais fortes, é isso[...]." (Ursa)

As respostas destas avós reforçando os aspectos positivos da amamentação remetem a outro achado ${ }^{(15)}$ sobre a dificuldade de obter respostas completas e confiáveis em entrevistas, uma vez que as mulheres entrevistadas pelos pesquisadores tendiam em responder de forma socialmente mais convincente.

É inegável que a amamentação traz consigo experiências positivas, mas traz também momentos negativos. Amamentar é uma condição obrigatória da maternidade e naturalmente deve ser encarada de forma edificante, como uma forma de reforçar o "amor materno"(20).

\section{Quinta subcategoria temática: o apoio à amamentação}

As avós mostraram-se presentes na amamentação de seus netos desde os momentos iniciais até a introdução de alimentos complementares. Aparentemente, a influência das mães e das sogras foi a mesma e, diferente do encontrado por outros autores ${ }^{(21)}$, não houve interferência negativa da maioria das avós que refletisse na duração da amamentação.

As experiências pessoais de sucesso das avós na AME foram importantes para a construção do apoio à nutriz adolescente. No entanto, as avós que não amamentaram mostraram-se reticentes sobre a função de apoio uma vez que detinham uma experiência pessoal limitada com a AM. 
A redução gradativa de bebês em AME no decorrer da pesquisa, tal como os achados de outros pesquisadores ${ }^{(22,23)}$, foi causadas segundo as falas das entrevistadas, por diferentes fatores como intercorrências mamárias comuns do início da amamentação, uso de chupetas, introdução de fórmulas, insegurança sobre a adequação da mamada e também o retorno à escola:

“[...] NESTOGENO (Nestlé, Campinas-SP), o pediatra falou que precisava, porque ela está só no peito e não sustentava [...] porque ela ficava pendurada e só mamava, mamava e mamava e nunca ficava satisfeita [...]."(Antilia)

As avós contornaram as intercorrências iniciais apoiadas em suas experiências pessoais e apontaram as orientações feitas no ambulatório como importantes na resolução de problemas. No entanto a prescrição médica para a introdução de fórmulas e outros alimentos também foi acatada:

“ [...] Está e não está [...] por conta dele ser prematuro, ela ficava nervosa porque ele não mamava, dai o pediatra do hospital mandou dar NAN (Nestlé, Campinas-SP) [...]." (Taurus)

Mesmo com todas as recomendações baseadas em inúmeras pesquisas científicas e políticas públicas de abrangência mundial e mobilização de agências internacionais (como a International Baby Food Action Network, por exemplo) para a manutenção do AME por seis meses $^{(4-6,15,16)}$, a introdução de alimentos próximos de 120 dias de vida do bebê por outros profissionais de saúde ainda é prática comum:

“[...] Sim e já estamos dando suco também [...] o pediatra disse que ela já estava com idade de suco." (Indus)

Outros pesquisadores ${ }^{(24,25)}$ apontam para a responsabilidade que os profissionais da saúde têm em orientar as práticas da alimentação complementar adequadas, que compreendem a introdução, em tempo oportuno, de alimentos complementares ao AM.

Interessante notar que as sugestões são chamadas pelas avós de "palpites", evitando qualquer fala enfática e ordenadora em relação à atitude de suas filhas ou noras:

"[...] Estou dando palpite, (risada) mas quem ensina mesmo são as enfermeiras[...]." (Monoceros)

Mães ou sogras, as avós demonstraram apoio e respeito pelas escolhas das mães adolescentes. Mantiveram-se presentes nos primeiros dias de puerpério, mas com passar do tempo colocaram-se na retaguarda, permitindo que as adolescentes assumissem a responsabilidade de principais cuidadoras.

Por volta da quarta entrevista, quando os bebês tinham quatro meses, foi possível perceber que a atuação das avós na amamentação deixou de ser incisiva. Estas mulheres retornaram as suas muitas atividades e a responsabilidade da alimentação e do cuidado com o neto é de inteira responsabilidade das próprias mães:

“ [...]Sim, agora vem a papa de sal e ela está meio triste [...] porque a nenê não gosta muito, mas eu já falei [...] nada, ela fez tudo sozinha[...]." (Phoenix)

O apoio das avós, fossem mães ou sogras, contribuiu para que algumas adolescentes amamentassem até o sexto mês, além do desejo afirmativo em fazê-lo, suporte familiar e orientações profissionais sobre o manejo da amamentação nas primeiras semanas de vida.

\section{CONSIDERAÇÕES FINAIS}

A prática do aleitamento materno foi descrita como uma experiência boa e importante na construção do apego ao filho. Sob o ponto de vistas das avós, amamentar é a ação esperada para uma mãe, não cabendo questionamento para o cumprimento deste papel.

As falas das entrevistadas levam a crer que os profissionais envolvidos na assistência pré-natal perdem ali a oportunidade importante em oferecer subsídios para que as adolescentes elaborem e escolham amamentar seus filhos.

Não houve imposição por parte das avós, mesmo daquelas que não amamentaram, sobre a alimentação dos bebês e couberam as adolescentes a decisão por outros tipos de leite orientados e prescritos por pediatras.

A influência das avós na amamentação de seus netos se deu pela crença compartilhada que amamentar é importante, saudável e uma obrigação da mãe.

Ao incluir pessoas significativas para a adolescente nas ações de promoção e proteção ao aleitamento materno, profissionais de saúde têm a oportunidade de ampliar o cuidado, unindo aspectos técnicos à experiência particular já vivida, para reforçar a rede de apoio à amamentação.

\section{REFERÊNCIAS}

1. Almeida JA, Novak FR. Amamentação: um híbrido natureza-cultura. J Pediatr. 2004;80(5 Supl):S119-25.

2. Organização Mundial da Saúde. Estratégia Global para a Alimentação de Lactentes e Crianças de Primeira Infância. São Paulo: IBFAN Brasil; 2007. [acesso em 2 Nov 2015]. Disponível em: http://www.ibfan.org.br/ documentos/ibfan/doc-286.pdf 
3. Victora CG, Bahl R, Barros AJ, França GV, Horton S, Krasevec J, et al. Breastfeeding in the 21st century: epidemiology, mechanisms, and lifelong effect. Lancet. 2016; 387(10017):475-90.

4. Ministério da Saúde (BR), Secretaria de Atenção à Saúde, Departamento de Ações Programáticas e Estratégicas. II Pesquisa de prevalência de aleitamento materno nas capitais brasileiras e Distrito Federal. Brasília: Ministério da Saúde; 2009.

5. American Academy of Pediatrics. Breastfeeding and use of human milk. Pediatrics. 2012;129(3):e827-41.

6. United Nations Children's Fund - UNICEF. The State of the World's Children 2015: reimagine the future [Internet]. 2015 [acesso em 2015 Nov 01]. Disponível em: http://www.unicef.org/publications/files/ SOWC_2015_Summary_and_Tables

7. Quiroga FL, Vitalle MSS. O adolescente e suas representações sociais: apontamentos sobre a importância do contexto histórico. Physis. 2013;23(3):863-78.

8. Ministério da Saúde (BR). Secretaria Executiva Departamento de Informática do SUS/DATASUS. Informações de Saúde. Estatísticas Vitais. Nascidos Vivos. 2014. [acesso em 2014 Fev 17]. Disponível em: http://www2.datasus.gov.br/DATASUS/index.php?are $\mathrm{a}=0205 \& \mathrm{id}=6936 \& \mathrm{VObj}=\mathrm{http}: / /$ tabnet.datasus.gov.br/ cgi/deftohtm.exe?sinasc/cnv/nv

9. Moreira M. Articulando gênero e geração aos estudos de saúde e sexualidade [Internet]. 2010 [acesso em 2014 Fev 06]. Disponível em: http://www.fazendogenero. ufsc.br/7/artigos/M/Maria_Ignez_Costa_Moreira_14. pdf

10. Landale NS, Thomas KJA, Hook JV. The living arrangements of children of immigrants. Future Child. 2011;21(1):43-70.

11. Silva NCB, Nunes CC, Mazzeto MCM, Rios KSA. Variáveis da família e seu impacto sobre o desenvolvimento infantil. Temas Psicol. 2008;16(2):215-29.

12. Turato ER. Métodos qualitativos e quantitativos na área da saúde: definições, diferenças e seus objetos de pesquisa. Rev Saúde Pública. 2005;39(3):507-14.

13. Bardin L. Análise de conteúdo. São Paulo: Edições 70; 2011.

14. Minayo MC. O desafio do conhecimento: pesquisa qualitativa em saúde. 14ª ed. São Paulo: Hucitec; 2014.
15. McInnes RJ, Chambers JA Supporting breastfeeding mothers: qualitative synthesis. J Adv Nurs. 2008;62(4):407-27.

16. Kim J, Mathai RA. Comparison of feeding practices in infants in the WIC Supplemental Nutrition Program who were enrolled in child care as opposed to those with parent care only. Breastfeed Med. 2015;10(7):371-6.

17. Rosen IMK, Krueger MV, Carney LM, Graham JA. Prenatal breastfeeding education and breastfeeding outcomes. MCN Am J Matern Child Nurs. 2008;33(5):315-9.

18. Takushi SAM, Tanaka ACA, Gallo PR, Machado MAMP. Motivação de gestantes para o aleitamento materno. Rev Nutr. 2008;21(5):491-502.

19. Sandre-Pereira G, Colares LGT, Carmo MGT, Soares EA. Conhecimentos maternos sobre amamentação entre puérperas inscritas em programa de prénatal. Cad Saúde Pública. 2000;16(2):457-66.

20. Badinter E. Um amor conquistado: o mito do amor materno. Rio de Janeiro: Nova Fronteira; 1985.

21. Susin LRO, Giugliani ERJ, Kummer SC. Inf=luência das avós na prática do aleitamento materno. Rev Saúde Pública, 2005; 39(2):141-7.

22. Rocha MG, Costa ES. Interrupção precoce do Aleitamento Materno exclusivo: experiência com mães de crianças em consultas de puericultura. Rev Bras Promoç Saúde. 2015;28(4):547-52.

23. Saliba NA, Zin LG, Moimaz SAS, Saliba O. Freqüência e variáveis associadas ao aleitamento materno em crianças com até 12 meses de idade no município de Araçatuba, São Paulo, Brasil. Rev Bras Matern Infantil. 2008;8(4):481-90.

24. Anjum Q, Ashfaq $\mathrm{T}$, Siddiqui $\mathrm{H}$. Knowledge regarding breastfeeding practices among medical students of Ziauddin University Karachi. J Pak Med Assoc. 2007;57(10):480-3.

25. Costa CRO, Meirelles RMS, Soares IC, Vieira EMS. Conhecimento e percepção dos acadêmicos do internato do curso de medicina sobre aleitamento materno. Rev Pedriatr SOPERJ. 2012;13(2):38-46.

\section{Endereço para correspondência:}

Patricia Helena Breno Queiroz

Faculdade de Jaguariúna - FAJ - Campus II

Rodovia Adhemar de Barros (SP-340), km 127

Bairro: Tanquinho Velho

CEP: 13.820-000 - Jaguariúna - SP - Brasil

E-mail: queirozphb@gmail.com 